\title{
UMA DISCUSSÃO SOBRE A VIABILIDADE DA PESQUISA-AÇÃO NA CONTABILIDADE
}

\section{A DISCUSSION ON THE FEASIBILITY OF RESEARCH -ACTION IN ACCOUNTING}

\author{
MAURELIO SOARES \\ Mestrando em Ciências Contábeis pela \\ Universidade Regional de Blumenau - FURB \\ Gaspar/ SC, Brasil \\ E-mail: maurelio.14@hotmail.com \\ ANANIAS FRANCISCO DOS SANTOS \\ Mestrando em Ciências Contábeis pela \\ Universidade Regional de Blumenau - FURB - Blumenau/SC, Brasil \\ E-mail: prof.ananias@gmail.com
}

\author{
CLAUDECIR PATON \\ Doutorando em Ciências Contábeis pela Universidade Regional de Blumenau-FURB \\ Professor da Universidade Estadual de Londrina, \\ Centro de Estudos Sociais Aplicados - Londrina/ PR, Brasil \\ E-mail: paton@uel.com \\ FRANCISCO ANTONIO BEZERRA \\ Doutor em Controladoria e Contabilidade pela Universidade de São Paulo \\ Professor do Programa de Pós-Graduação em Ciências Contábeis da \\ Universidade Regional de Blumenau - FURB - Blumenau/SC, Brasil \\ E-mail: fbezerra@furb.br
}

\section{RESUMO}

\begin{abstract}
Discute-se neste trabalho a possibilidade de aplicação da Pesquisa-Ação na solução de problemas detectados em ambientes organizacionais, tendo assim como objetivo demonstrar a eficiência da Pesquisa-Ação na contabilidade, como metodologia formadora de soluções para tais ambientes. A abordagem do problema caracteriza-se como qualitativa e a metodologia de pesquisa utilizada neste trabalho fundamenta-se na Pesquisa-Ação, em razão do autor ser um participante ativo e com ações reais no trabalho final implementado na instituição pesquisada, a qual é um hospital filantrópico. Aplicaram-se as quatro fases da Pesquisa-Ação definidas no referencial teórico, quais sejam: exploratória, aprofundada, ação e avaliação, sendo apresentado o resultado com as devidas considerações em cada uma das quatro fases, bem como ao final. Constatou-se a importância da pesquisa-ação, tendo em vista que além de solucionar o problema detectado, ainda sugeriu algumas mudanças que são importantes para a administração da entidade, além de provê-la com informações úteis e fundamentais para o sucesso daquela instituição no controle do seu patrimônio. Por outro lado, este trabalho demonstrou a viabilidade da Pesquisa-Ação na contabilidade, enquanto técnica de pesquisa, cuja capacidade de superar impasses entre teoria e prática, por meio da interação e exploração de ambas, é capaz de formar soluções para os ambientes organizacionais.
\end{abstract}

Palavras-chave: Pesquisa-Ação. Gestão. Ambientes Organizacionais.

\section{ABSTRACT}

It is discussed in this research the possibility of application of Research-Action in the solution of problems encountered in organizational environments, and the objective is to show the effectiveness of Research-Action in accounting, as a methodology which could promote solutions for such environments. The approach of the problem is characterized as qualitative research and the methodology used in this work is based in Research-Action, because the author is an active participant and execute real actions in the final work implemented in the institution studied, which is a philanthropic hospital. There had been applied the four phases of Research-Action defined in the theoretical framework, which are: exploratory, depth, action and evaluation, and it was presented a result with the appropriate considerations in each of the four stages and in the end as well. It was verified the importance of Research-Action, since in addition to solving the problem detected, it was also suggested some changes that are important to the administration of the entity, and provides it with useful and essential information to the success of that institution in control of its property. Furthermore, this research demonstrated the viability of Research-Action in accounting as a technique of research, whose ability to overcome impasses between theory and practice, through interaction and exploration of both, is capable of forming solutions to organizational environments.

Keywords: Research-Action. Management. Organizational Environments. 


\section{INTRODUÇÃO}

$\mathrm{Na}$ busca da melhor formação de profissionais em ciências contábeis, especialmente nos cursos de pós-graduação latu e strictu sensu, são exigidas apresentações de teses, dissertações, artigos etc., sustentadas pela pesquisa e metodologia científica. A partir da produção do saber científico trazido pelo mundo acadêmico, torna-se possível transformar o conhecimento científico numa ação transformadora, em que a realidade e suas interpretações geram novos conceitos passíveis de aplicação nas organizações.

Enquanto Ciência, a Contabilidade deve correr o risco de demonstrar sua capacidade de gerar novos marcos teóricos que possam ser aplicáveis, ou seja, que a Contabilidade seja útil para a sociedade (LOPES et al, 2006). Nesse contexto surge a discussão da metodologia de Pesquisa-Ação como uma ferramenta importante para a Contabilidade, que promove a criação de soluções passíveis de implementação, a partir dos achados conceituais préexistentes.

De acordo com Lopes et al (2006), a Pesquisa-Ação proporciona a construção de conceitual atrativo para a ciência contábil, que permite aproximar, por meio de ação transformadora, o que é com o que deveria ser. Parte-se do pressuposto que a Pesquisa-Ação é um método de pesquisa que incrementa de forma intensa e relevante a participação da ciência contábil na produção de um conhecimento novo e útil.

Já para Martensson e Lee (2004, p.509), “o que na ciência seria apenas um estímulo experimental, na pesquisa-ação ela simultaneamente intervém, cria uma ação e repara um caso concreto, fruto de uma teoria com base científica".

Susman e Evered (1978, p. 601) acreditam que "a pesquisa-ação tem, em termos de ciência positivista, um grande potencial para entender e gerenciar organizações."

Diante dessa contextualização, surge a seguinte questão: é possível aplicar a PesquisaAção na solução de problemas detectados em ambientes organizacionais? Dessa forma, o presente artigo tem como objetivo demonstrar a eficiência da Pesquisa-Ação na contabilidade, como metodologia formadora de soluções para os ambientes organizacionais.

Com relação à abordagem do problema, essa pesquisa caracteriza-se como qualitativa. Já quanto à metodologia de pesquisa utilizada neste trabalho, fundamenta-se na PesquisaAção, em razão de o autor ser um participante ativo e com ações reais no trabalho final implementado na instituição pesquisada, gerando conhecimento teórico para aplicação prática, na solução dos problemas específicos ao caso em questão.

0 artigo está estruturado em cinco seções, iniciando com a introdução ao estudo, fazendo-se, em seguida, uma incursão nos referenciais teóricos voltados aos níveis de geração do conhecimento e a pesquisa-ação. No terceiro tópico é descrita a metodologia empregada e, em seguida, o resultado da pesquisa com a aplicação de um caso de pesquisa-ação em suas fases e, por fim, a conclusão.

\section{REFERENCIAL TEÓRICO}

A atual literatura contempla a concepção que, a geração de todo o conhecimento ocorre em quatro níveis ou pólos, dispostos na seguinte ordem: pólo epistemológico, pólo teórico, pólo metodológico e pólo técnico. 0 referencial epistemológico orienta a direção do referencial teórico que, por sua vez, encaminha as orientações metodológicas, que 
influenciam o pólo técnico (BRUYNE et al, 1991).

Segundo Gamboa (1987, p. 61) "no percurso de todo processo de pesquisa científica, articulam-se problemas de índole epistemológica, problemas teóricos, problemas metodológicos e problemas técnicos". Esse paradigma sugere que a observação de algumas características que são fundamentais num trabalho permite sua classificação em uma das abordagens que trataremos.

Bruyne et al . (1991) também concebem o campo da prática científica como um espaço quadripolar. Importante destacar que há divergências entre essas concepções, que vão desde a não inclusão de alguns pólos e categorias metodológicas, até diferenças na hierarquização dos pólos. Concorda com a flexibilidade dos elementos que influenciam a prática científica. 0 espaço científico é considerado como um campo dinâmico, que é sujeito a distintos pólos ou instâncias.

Na Figura 1, é feita uma adaptação da ilustração contida em Bruyne et al (1991), para representar o modelo paradigmático. Da configuração original, foi mantida a idéia de um modelo quadripolar, com setas indicativas da natureza dinâmica e não-cronológica do modelo.

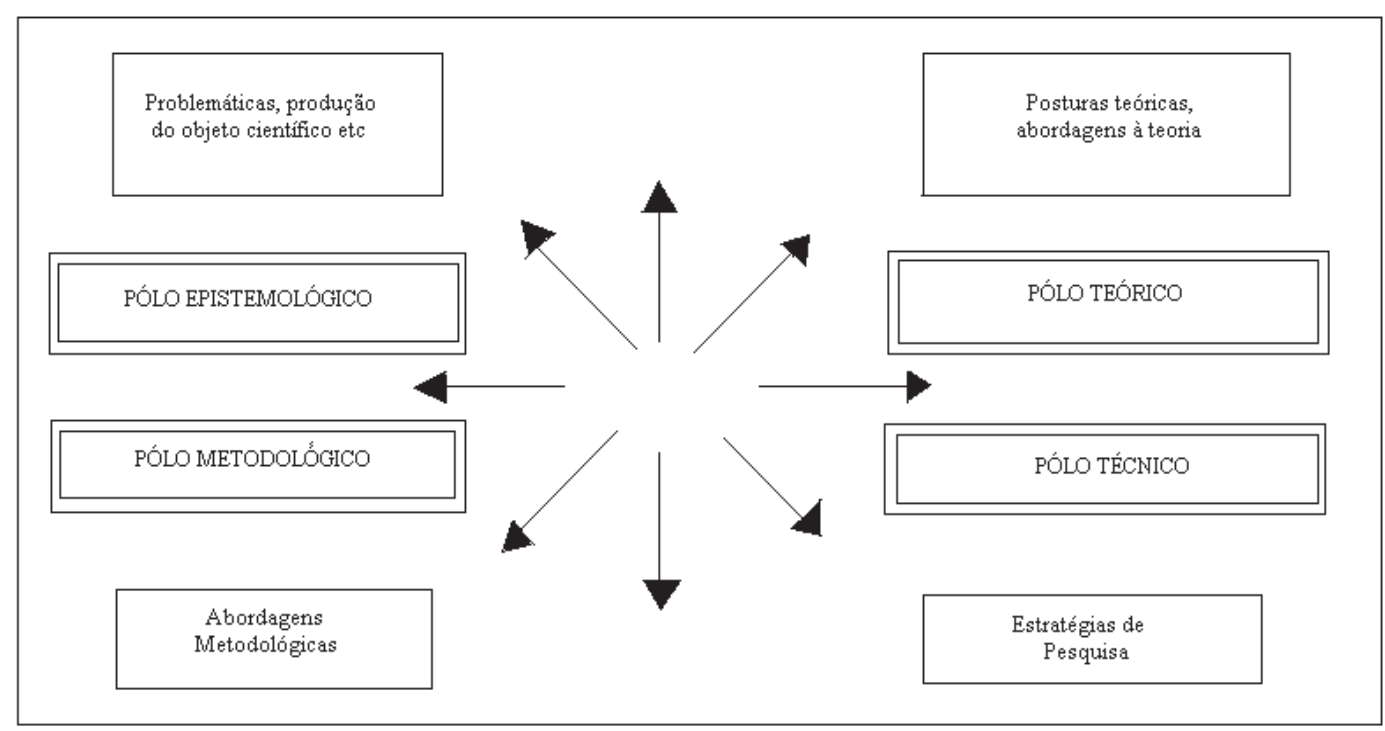

Figura 1 - Esquema paradigmático

Fonte: Adaptado de Bruyne et al (1991)

Bruyne et al (1991) explica que o pólo epistemológico exerce uma função de vigilância crítica da pesquisa. Nele são discutidas questões como a explicitação das problemáticas de pesquisa e a produção do objeto científico; e consideradas concepções com as de causalidade, validação e cientificidade.

Afirmam ainda os autores, que a epistemologia interna nasce sob os próprios passos do cientista, exigida por problemas que se colocam no interior de cada ciência. Já a epistemologia geral é fruto da troca interdisciplinar das reflexões epistemológicas internas das diversas disciplinas.

Bunge (1974) afirma que o pólo teórico é o lugar da elaboração das linguagens científicas, orientando a definição das hipóteses e construção dos conceitos. Compreende aspectos como teorias, modelos, formas de enunciação, programas de desenvolvimento científico, hipóteses etc.

Nesse pólo, considera a existência de dois tipos de programas na evolução do desenvolvimento científico. O primeiro, o programa de investigação em superfície, que 
compreende o aumento de conhecimento rotineiro baseado nas crenças existentes e voltado ao aprimoramento de teorias tradicionalmente aceitas dentro de uma comunidade científica. O segundo, o programa de investigação em profundidade, que consiste na proposição de idéias a partir de novas visões e perspectivas.

O pólo metodológico contempla dimensões relacionadas com os diversos modos de tratar a realidade. É a instância que inclui as maneiras por meio das quais se busca a explicação para os fenômenos estudados. Esse pólo inclui dimensões amplas, como as seguintes abordagens metodológicas: empirismo, positivismo, abordagem sistêmica estruturalismo, dialética e fenomenologia. (BRUYNE et al, 1991).

O pólo técnico guia os procedimentos de coleta de dados e sua transformação em informações pertinentes à problemática de pesquisa. Esse pólo está diretamente ligado às estratégias ou delineamentos de pesquisa, e as técnicas para coleta de informações, dados, evidências. Partem-se daqui as escolhas práticas feitas pelos pesquisadores para permitir o encontro com os fatos empíricos.

A discussão sobre dos aspectos relacionados ao pólo técnico, é realizada com base no conceito de design abordado por Kidder (1987), que corresponde ao planejamento e estruturação da pesquisa em sua dimensão mais ampla, compreendendo tanto a diagramação quanto a previsão de coleta e análise de dados.

A esse propósito Martensson e Lee (2004) enfatizam que a dimensão empírica da ciência se dá quando uma teoria pode ser aplicada com rigor científico, nesse caso, a pesquisa-ação investiga e é empregada num problema do mundo real. É no pólo técnico que se encontra a Pesquisa-Ação, objeto central do presente estudo.

\subsection{PESQUISA-AÇÃO: UM BREVE HISTÓRICO}

Procurando entender as origens da Pesquisa-Ação, toma-se como ponto de partida a visão de Kurt Lewin, pesquisador que desenvolveu estudos nas áreas da Filosofia da Ciência, da Psicologia e da Ciência Social.

De acordo com Pereira (2003), seus primeiros trabalhos analisavam comportamentos individuais. Anos mais tarde, devido a novas responsabilidades profissionais e envolvimento em projetos sociais patrocinados pelo governo norte-americano que buscava mudar os hábitos alimentares dos americanos, Lewin constatou a importância dos grupos na mudança e no comportamento individual.

Participando e conduzindo em vários projetos que gerassem uma mudança organizacional e social, Lewin comprovou que, do ponto de vista da ação, a pesquisa científica era possível de aplicação. As suas orientações metodológicas apoiaram-se na importância do meio social para então compreender o indivíduo, procurando mudar a realidade para o desenvolvimento da teoria, e como consequência, assumir que a principal finalidade da teoria é reordenar e melhorar as situações do mundo real (PEREIRA, 2003).

Com esse modelo, Lewin concebeu a Pesquisa-Ação como um posicionamento realista da ação, sempre seguida por uma reflexão autocrítica e objetiva e uma avaliação dos resultados (PEREIRA, 2001).

Passados 50 anos que Kurt Lewin propôs a idéia de pesquisa-ação, o termo permanece uma espécie de "guarda-chuva" para abrigar várias atividades que pretendem promover mudança no grupo, sejam nas organizações ou nos demais segmentos da sociedade. (LINDA e KAREN, 1999). 
A partir da definição de Lewin várias outras subsequentes mostram que outros autores mudaram a delimitação original para destacar diversos aspectos do processo de PesquisaAção.

Argyris (1992, p. 86) destaca que as “intervenções são uma manipulação experimental e a resolução do problema é a meta”. Elden e Chisholm (1993) focalizam-se na adaptação de sistemas e na habilidade para inovar. No entanto, a maioria dos investigadores de ação concorda que Pesquisa-Ação consiste em ciclos de planejamento, ação, reflexão ou avaliação, e mais adiante ação.

\subsection{PESQUISA-AÇÃO: UMA DEFINIÇÃO E SUAS UTILIDADES}

A Pesquisa-Ação tem sido definida como um tipo de investigação participante que tem como característica peculiar o propósito de ação planejada sobre os problemas detectados. Thiollent (2002, p.20) descreve que na Pesquisa-Ação, “os atores envolvidos participam junto com os pesquisadores para chegarem interativamente a elucidar a realidade em que estão inseridos, identificando problemas coletivos, buscando e experimentando soluções em situação real”.

Consideram-se "atores" pessoas que dispõem de capacidade de ação coletiva consciente em um determinado contexto social, organizadas tanto em grupos informais como em grupos formalmente constituído.

Quanto à importância do conhecimento científico do pesquisador, seu comportamento torna-se mais influente e tende a servir como modelo de ação em caso de situações não programadas. (SUSMAN; EVERED, 1978)

A aplicação da Pesquisa-Ação nos estudos das organizações abrange particularmente a área de administração de pessoal e fatores relacionados às características culturais e sociais da tecnologia e da inovação técnica.

Segundo Scott (2002) a pesquisa-ação busca melhorar a prática organizacional por meio de um caminho sistemático, que quando necessário, sofrerá alterações ou intervenções. Ele combina ação e investigação, através das fases de espiral: planejamento, ação, observação e reflexão. Essa modalidade de pesquisa não se destina a ser aplicada na solução quotidiana de pequenos problemas gerenciais ou administrativos; ao contrário, é destinada a tratar questões complexas, especialmente em situações insatisfatórias ou de crise, que têm características de diagnóstico e de consultoria (THIOLLENT, 1997).

Segundo Martensson e Lee (2004, p.532) “o pesquisador tem a opção de envolver-se diretamente nas atividades da organização em que haja um problema a ser resolvido, ou uma situação a ser melhorada".

Como destaca Thiollent (2002), um grande desafio consiste em fundamentar a inserção da Pesquisa-Ação dentro de uma perspectiva de investigação científica, concebida de modo aberto e na qual ciência não seja sinônimo de positivismo, funcionalismo ou de outros rótulos.

Importante destacar que de acordo com o método de Pesquisa-Ação, a formulação do problema de maneira mais específica deve ser parte do próprio processo de investigação, fruto da interação com os atores envolvidos no processo. Gajardo (1986, p. 32), afirma que:

Basicamente são os participantes que, através da discussão das unidades, objetivam um problema do meio, problematizam sua situação, colocam-se 
como sujeitos ativos e protagonistas, buscando, a partir de sua experiência e realidade, um caminho de ação eficaz para enfrentá-los.

Supõe-se que a principal definição quanto à utilidade da Pesquisa-Ação, está em caracterizá-la como "pesquisa contábil transformadora", isto é, a partir do confronto da realidade organizacional, aplicando-se o intercâmbio de experiências, a concepção de verdades e soluções, levará a uma melhor competitividade na organização.

\subsection{CARACTERÍSTICAS DA PESQUISA-AÇÃO}

Segundo Kurt Lewin (1948 apud PEREIRA, 2003), Pesquisa-Ação se constitui em um ciclo de análise, fato achado, concepção, planejamento, execução e mais fato-achado ou avaliação. E então, uma repetição deste círculo inteiro de atividades, realmente uma espiral de tais círculos.

Martins e Theóphilo (2007, p.72) afirmam que "a realização de uma Pesquisa-Ação é facilitada nas organizações de cultura democrática, quando já existe o reconhecimento e participação de todos os grupos. Em um Estudo de Caso a autorização dos responsáveis pela organização que se pretende realizar a pesquisa, em tese, possibilita a condução de uma Pesquisa-Ação".

Esses autores enumeram as seguintes características de uma Pesquisa-Ação:

a) há uma ampla e explícita interação entre o pesquisador e pessoas implicadas na situação investigada; b) da interação resulta a ordem de prioridade dos problemas a serem pesquisados e das soluções a serem encaminhadas sob a forma de ação concreta; c) o objeto da investigação não é constituído pelas pessoas e sim pela situação social e pelos problemas de diferentes naturezas encontrados; d) o objetivo de uma PA consiste em resolver ou, pelo menos, em esclarecer problemas da situação observada; e) há, durante o processo, um acompanhamento das decisões, das ações, e de todas as atividades intencionais dos atores da situação; f) a pesquisa não se limita a uma forma de ação (risco de ativismo): pretende aumentar o conhecimento do pesquisador sobre o nível de consciência das pessoas e dos grupos considerados. (MARTIN; TEÓPHILO, 2007, p.71)

Segundo Thiollent (2002), Pesquisa-Ação é um tipo de pesquisa social com base empírica que é concebida e realizada em estreita associação com uma ação ou com a resolução de um problema coletivo e no qual os pesquisadores e os participantes representativos da situação ou problema estão envolvidos de modo cooperativo ou participativo.

Para Lindgren, Henfridsson e Schultze (2004, p. 441) “a pesquisa-ação é um método de intervenção que permite ao pesquisador um teste da hipótese sobre o fenômeno de interesse, por meio da implementação, da avaliação, de mudança e de aj uste em um mundo real".

Lau (1999) sugere a necessidade da participação de um pesquisador com conhecimentos específicos para orientar o esforço e para esclarecer detalhes metodológicos, tais como o papel do pesquisador, o processo de diagnóstico de problemas, a natureza da intervenção, o grau de reflexão e aprendizagem pretendido, e perceber se há um conhecimento novo a ser adquirido.

Entende-se, portanto, que autor da pesquisa e os atores sociais encontram-se reciprocamente implicados: os atores na construção e resultados da pesquisa e o autor nas ações que irão orientar a pesquisa e seus achados. Autor e atores tendem a identificarem-se em uma só instância de planejamento e operações. 
Os atores de um Estudo de Caso deixam de ser simplesmente objeto de observação, de explicação ou de interpretação. Eles se tornam suj eitos e parte integrante da pesquisa, de sua concepção, de seu desenvolvimento, de seus resultados e de sua redação. É fundamental conjugar interesses do pesquisador com as expectativas dos atores.

Uma Pesquisa-Ação comporta três aspectos simultâneos, se analisada como pesquisa inserida na ação, conforme afirma Thiollent (1997, p.37):

(a) Pesquisa SOBRE os atores sociais, suas ações, transações, interações; seu objetivo é a explicação; (b) pesquisa PARA dotar de uma prática racional as práticas espontâneas; seu objetivo é a aplicação. (c) Pesquisa POR, ou melhor, PELA ação, isto é, assumida por seus próprios atores (autodiagnóstico e autoprognóstico) tanto em suas concepções como em sua execução e seus acompanhamentos; seu objetivo é a implicação.

Além dos três tipos de pesquisas correspondentes à explicação, aplicação e o efeito, Thiollent (1997, p. 38) afirma que a Pesquisa-Ação se estrutura em cinco dimensões:

1) Contrato, que pode ser informal entre o pesquisador e atores e consiste em definir os objetivos de conhecimento e mudança; 2) Participação, que varia entre as formas de colaboração, cooperação ou co-gestão; 3) Mudança, deriva da aplicação de uma teoria, de um processo de cooperação ou de co-gestão; 4) Discurso, pode ser espontâneo, esclarecido ou engajado; e 5) Ação, que apresenta aspectos individuais, coletivos ou comunitários.

Afirma o autor, tanto com relação às cinco dimensões da Pesquisa-Ação apresentadas anteriormente, no que diz respeito à tipologia das modalidades de articulação entre a pesquisa e os autores (pesquisadores) e, a ação e os atores, que existe multiplicidade de configurações a serem escolhidas, elaboradas ou adaptadas em função das situações concretas da investigação e das ações possíveis.

A Pesquisa-Ação descrita por Lewin (1948 apud PEREIRA, 2003) acontece numa espiral formada por: planejamento, ação e avaliação dos resultados da ação. Seu processo parte do princípio de que uma melhoria ou mudança em uma área de trabalho do profissional é desejável. Um grupo então é criado para elucidar a preocupação mútua que foi identificada e, em seguida, decide por trabalhar em conjunto focando estratégias de melhoria (ação) no tema de maior interesse.

Hatten, Knapp e Salonga (1997), detalham a Pesquisa-Ação como uma espiral na seguinte forma:

1) Desenvolvem um plano de ação com informações críticas para melhorar as práticas atuais. 0 plano deve ser flexível para permitir adaptação para efeitos imprevistos ou restrições; (2) Os membros do grupo agem para implementarem o plano, o qual deve ser discutido e controlado; (3) A ação é observada para coletar evidências que permitam uma avaliação completa. A observação deve ser planejada e um diário pode ser utilizado para o propósito de registro. O processo de ação e seus efeitos dentro do contexto da situação devem ser observados individual ou coletivamente; (4) A Reflexão sobre a ação registrada durante observação normalmente é auxiliada pela discussão entre os membros do grupo. As reflexões podem levar à reconstrução do entendimento da situação social e fornecem uma base para planejamento futuro de ações criticamente informadas, assim 0 ciclo continua. Estes passos são executados de um modo mais cuidadoso, sistemático e rigoroso do que normalmente acontece na prática diária.

Martins e Theóphilo (2007, p.73) têm um posicionamento semelhante, pois entendem que a concepção de uma Pesquisa-Ação é vista como uma estrutura de interação clientes/ pesquisador, com procedimentos em cinco fases: 
1) diagnóstico para identificar um problema na organização; 2) planejamento do estudo considerando as ações alternativas para resolver o problema; 3) execução das ações planejadas com seleção de roteiros e estratégias; 4) avaliação das conseqüências de cada ação; 5) aprendizagem específica e identificação dos ensinamentos da experiência, com retomo ao ponto de partida para evidenciar o conhecimento generalizável adquirido sobre 0 problema.

A pesquisa-ação facilita o desenvolvimento de "práticas culturais", pois, proporciona ao pesquisador formas e configurações próprias para criar um ambiente de aprendizagemorganizacional como, por exemplo, a inclusão de ações onde não existia, revisão de processos, redefinição de funções etc. (SUSMAN; EVERED, 1978).

Diante das perspectivas positivas para implantação da "pesquisa contábil transformadora", após a descrição dos principais aspectos e características, a seguir apresenta-se uma proposta de estrutura metodológica para o desenvolvimento de uma Pesquisa-Ação na Contabilidade.

\subsection{FASES DA PESQUISA-AÇÃO}

Buscando estudar a viabilidade do uso da pesquisa-ação no desenvolvimento de sistemas de informação, Lau (1999, p. 150) descreve que "o mais exclusivo aspecto da pesquisaação está no seu processo iterativo de diagnóstico de problemas, na ação, intervenção e aprendizagem reflexiva pelo pesquisador e participantes".

Segundo Gopal e Prasad (2000), na recente literatura sobre pesquisa-ação, têm-se observado uma generalização sobre os critérios de validade da pesquisa-ação, os quais indicam fases, que variam em número, mas que são cíclicos e reaplicáveis em movimento espiral.

Embora não se tenha uma forma totalmente predefinida, pode-se dizer que existam no mínimo quatro grandes fases na condução de um projeto de Pesquisa-Ação (MARTINS E THEÓPHILO, 2007).

\section{a) Fase exploratória}

A exploração se pratica essencialmente pela discussão em grupo com membros da organização na identificação do problema proposto pelo pesquisador que possa ser cientificamente solucionado pela ação do autor e atores envolvidos, podendo iniciar-se sob a forma de simples conversação e prolongar-se em entrevistas individuais, coletivas ou em seminários. Para Martins e Theóphilo (2007 p.73) nesta fase, as principais atividades relacionadas com a entrevista são:

1) Preparação do roteiro de entrevista; 2) Preparação do trabalho da equipe de entrevistadores, ou do próprio pesquisador; 3) Aplicação do roteiro de entrevista; 4) Análise e interpretação das respostas; 5) Relatório de análise das entrevistas; 6) Retorno do relatório aos entrevistados.

\section{b) Fase da pesquisa aprofundada}

Martins e Theóphilo (2007, p. 73) afirmam que "nesta fase o pesquisador e participantes se reúnem em um seminário para direcionar a investigação, com auxílio de grupos de estudos de coleta de dados". Quando da aplicação de uma Pesquisa-Ação em organização empresarial o grupo permanente é composto dos promotores da pesquisa, de 
membros da gerência representativa de diversas áreas e, eventualmente, de consultores ou pesquisadores externos.

Entre as principais atribuições do grupo permanente destacam-se: entendimento dos temas e problemas prioritários; compreensão da problemática, das proposições e eventuais hipóteses da pesquisa; coordenação das atividades; centralização das informações provenientes das diversas fontes; interpretação dos resultados; busca de soluções e propostas de ação; acompanhamento das ações implementadas e avaliação dos resultados; divulgação dos resultados por meio de canais adequados, com estilo de redação adequado aos públicos leitores.

\section{c) Fase da ação}

A fase de ação tem como objetivo difundir os resultados, que, além de informativos, devem ser conscientizadores. O processo de divulgação pode ser concebido de dois modos: centralizado por equipe dotada de autonomia ou descentralizado em função da própria estrutura da organização (MARTINS; THEÓPHILO, 2007, p.73).

Uma vez processados os resultados da pesquisa é aberta uma ampla discussão entre os membros da organização e diversas propostas são encaminhadas em termos de aperfeiçoamentos e/ ou mudanças.

\section{d) Fase de avaliação}

Martins e Theóphilo (2007, p. 74), apresentam a fase de avaliação onde as ações implementadas são objeto de profunda avaliação acompanhada por grupos conjuntos e sintetizadas em seminários nos quais podem ser convidados avaliadores externos. Assim como aspectos da pesquisa que podem ser obj eto de avaliação destacam-se:

1) Pontos estratégicos, 2) Capacidade de mobilização, 3) Capacidade de geração de propostas, 4) Continuidade de projeto, 5) Participação, 6) Qualidade do trabalho em equipe, 7) Efetividade das atividades de formação,

8) Conhecimento e informação, 9) Comunicação e 10) Atividades de apoio.

Existem poucas experiências de Pesquisa-Ação nas organizações e empresas no Brasil, devido, segundo Thiollent (1997), à forma de gestão autoritária e pouco participativa das nossas empresas, nas quais o problema social é visto como questão de disciplina ou polícia.

A pesquisa-ação tem sido tratada como "um método de investigação científica póspositivista social, de preferência adaptado a um estudo de tecnologia no seu contexto humano “(BASKERVILLE; WOOD-HARPER, 1996, p. 235).

Segundo Susman e Evered (1978, p.599) "a partir do modelo de processo criado pelo pesquisador, o padrão aplicado pode ser reaplicado em outras organizações".

Importante destacar a diferença entre Consultoria e Pesquisa-Ação, quando Pereira (2003, p. 157) afirma que "o processo da pesquisa-ação e os processos típicos de consultoria organizacional contêm semelhanças substanciais em função das principais literaturas sobre ambos se reportarem ao trabalho inicial de Kurt Lewin”.

Enquanto que a Pesquisa-Ação é motivada por propósitos científicos que se compromete em produzir um novo conhecimento e, por conseguinte, auxiliar a empresa a implantar novas soluções. A Consultoria é paga para ditar soluções anteriormente experimentadas e confiáveis, embasadas em opinião própria. 


\section{METODOLOGIA}

Neste item apresentam-se a aplicação do método e os procedimentos da pesquisa. Quanto aos obj etivos da pesquisa esse artigo pode ser caracterizado como pesquisa aplicada, uma vez que, nela, o investigador é movido pela necessidade de contribuir para fins práticos, mais ou menos imediatos, buscando soluções para problemas concretos.

Em relação à abordagem do problema, essa pesquisa caracteriza-se como qualitativa. Já quanto à metodologia de pesquisa utilizada neste trabalho se fundamenta na PesquisaAção, em razão do autor ser um participante ativo e com ações reais no trabalho final implementado na instituição pesquisada, gerando conhecimento teórico para aplicação prática, na solução dos problemas específicos ao caso em questão.

\subsection{BREVE HISTÓRICO DA ENTIDADE EM ESTUDO}

Por se tratar de uma entidade hospitalar de natureza filantrópica, faz-se necessária uma breve incursão sobre detalhes importantes sobre este tipo de entidade, como segue:

A Lei das OSCIPs ( $n^{\circ}$. 9.790/99) institui que podem se qualificar como Organizações da Sociedade Civil de Interesse Público as pessoas jurídicas de direito privado, sem fins lucrativos, desde que os respectivos objetivos sociais e normas estatutárias atendam aos requisitos de não distribuir, entre os seus sócios ou associados, conselheiros, diretores, empregados ou doadores, eventuais excedentes operacionais, brutos ou líquidos, dividendos, bonificações, participações ou parcelas de seu patrimônio auferido mediante o exercício de suas atividades, e que os apliquem integralmente na consecução do objeto social da entidade.

Assim uma entidade filantrópica beneficente de assistência social, de acordo com - Conselho Nacional de Assistência Social, é caracterizada quando atua para: a) proteger a família, a maternidade, a infância, a adolescência e a velhice; b) amparar crianças e adolescentes carentes; c) promover ações de prevenção, habilitação e reabilitação de pessoas portadoras de deficiências; d) promover, gratuitamente, assistência educacional ou de saúde; e) promover a integração ao mercado de trabalho; e f) promover o atendimento e o assessoramento aos beneficiários da Lei Orgânica da Assistência Social e a defesa e garantia dos seus direitos.

Observa-se que as entidades filantrópicas exploram as mais diversas atividades de prestação de serviços, dentre as quais está a de saúde, assim desde que respeitado os requisitos necessários, a entidade objeto deste estudo, está incluída nesta classificação de entidade filantrópica, sendo necessário apresentar a seguir seu objeto e objetivos.

Segundo Colauto e Beuren (2003), as organizações hospitalares têm papel preponderante a cumprir na construção de um mundo novo, devendo, para tanto, também assumir responsabilidades sociais para com a comunidade.

Apontam para a semelhança do hospital para com uma empresa, que possui os mesmos problemas da sistemática global do empreendimento capitalista, na ordem legal, administrativa, trabalhista e principalmente na obtenção de receitas para suprir suas despesas e ainda possibilitar uma maximização do superávit financeiro para fazer frente à evolução tecnológica necessária ao ramo médico hospitalar, bem como manter seu capital estrutural.

De modo genérico, o objeto social da empresa hospitalar é definido como sendo 
[...] fixado com base na idéia que os membros constitutivos têm sobre o ramo de especialização a ser explorado. Assim, ao se formar uma instituição filantrópica com a finalidade de atuar no campo hospitalar, é muito provável que o objeto social envolvido seja proveniente da necessidade que um grupo de pessoas observou como carência de uma comunidade. Portanto, a alusão é específica à prestação de serviços (COLAUTO; BEUREN, 2003).

Já os objetivos constitutivos das organizações hospitalares, segundo Colauto e Beuren (2003) compreendem a captação, administração e maximização dos recursos, a fim de oportunizar o contínuo atendimento médico. Reportando-se aos aspectos gerenciais dessas organizações enquadradas como entidades beneficentes, além de cuidar dos aspectos do ambiente interno, devem considerar os elementos estratégicos norteadores do atual ambiente econômico.

Concluem os autores que para a entidade hospitalar tenha sucesso na sua administração, deve ter melhor aproveitamento racional dos recursos estruturais, humanos e de clientes, necessitando, assim, que as estratégias operacionais específicas sejam remetidas em direção da realização destes objetivos institucionais da entidade.

Observa-se desta breve incursão sobre a filantropia e o serviço médico hospitalar prestado por tais entidades, a real semelhança com outras empresas, que não no aspecto filantrópico e sem fins lucrativos, mas principalmente no aspecto de sobrevivência econômica, pois o simples fato de considerar uma entidade filantrópica ou sem fins lucrativos, não pode em hipótese alguma supor que tal entidade possa se manter em atividade para o bem de uma sociedade que depende das suas atividades, sem a obtenção de receitas e a administração coerente para maximização dos seus recursos, materiais, financeiros e humanos.

A entidade em estudo, que por motivos de confidencialidade, será aqui apresentada como EE (Entidade em Estudo), é uma instituição filantrópica sem fins lucrativos, fundada em 1965, que oferece tratamento de todo tipo de câncer a nível ambulatorial e hospitalar.

No ano de 2005, a EE atendeu 66.487 pacientes, oriundos de 226 municípios do seu Estado e 26 municípios de outros estados. Do total de pacientes atendidos, 58,85\% eram da própria cidade e região e os restantes $41,15 \%$ de outros municípios, o que ressalta a importância da EE não apenas para a região, mas, para todo o Estado em que ela está sediada.

\section{RESULTADO DA PESQUISA}

Apresenta a seguir a discussão dos dados obtidos, ressaltando-se que os resultados comentados a seguir referem-se unicamente à aplicação da Pesquisa-Ação na Entidade em Estudo (EE) e, portanto, não podem ser generalizados a outros ambientes organizacionais.

\subsection{FASE EXPLORATÓRIA}

A fase exploratória conforme Martins e Theóphilo (2007) é praticada essencialmente pela discussão em grupo com membros da organização na identificação do problema proposto pelo pesquisador que possa ser cientificamente solucionado pela ação do autor e atores envolvidos, podendo iniciar-se sob a forma de simples conversação e prolongar-se em entrevistas individuais, coletivas ou em seminários.

Observe-se que os autores afirmam que esta fase pode iniciar-se sob a forma de 
simples conversação e prolongar-se em entrevistas individuais, coletivas ou em seminários, e para tanto relaciona as principais atividades relacionadas com a entrevista, não deixando transparecer em nenhum momento como seria a forma de simples conversação.

Também Thiollent (1997) demonstra duas possibilidades, podendo ser o contrato formal ou informal, entre os pesquisadores e os atores nesta fase inicial, no sentido de definir os objetivos de conhecimento e de mudanças. 0 aspecto formal está em incluir em suas tarefas a utilização de técnicas de entrevistas e questionários, que geralmente em organizações de grande dimensão e com predominâncias do tipo burocrático seriam de mais fácil aceitação.

Já no aspecto informal seria um proj eto baseado em trabalho de grupos e discussão ou de outros dispositivos mais abertos. Feitas estas considerações, esclarece-se que o presente estudo pautou-se pela utilização da segunda opção, ou seja, informal, e por tanto não seguiu a formalidade dos questionários e entrevistas propostos por Martins e Theóphilo (2007).

A EE tem a necessidade de manter o controle analítico de seus bens patrimoniais, bem como seus registros contábeis, sempre atualizados, de forma que venham a atender as necessidades de informações por parte de sua administração.

No início do ano de 2006, a diretoria administrativa da EE, com a finalidade de expor problemas de ordem administrativa para atendimento às solicitações do Conselho Fiscal quanto aos seus itens patrimoniais, entrou em contato com o responsável pelo Grupo de Estudo realizador deste.

Agendou-se então uma reunião cuja pauta principal foi a resolução do problema do controle patrimonial dos itens do imobilizado da $E E$, o qual há muito tempo não era realizado. Assim, nesta fase exploratória o autor, responsável pelo GE, utilizando-se do aspecto informal iniciou o projeto baseado em trabalhos de grupos de discussão e outros dispositivos mais abertos.

Nesta oportunidade foi detectado que a EE não possuía controle dos itens patrimoniais, o que ocasionavam as seguintes situações:

1) Valor e itens contabilizados diferente dos bens patrimoniais real mente existentes, com incorreções nas Demonstrações Contábeis da entidade;

2) itens patrimoniais não localizados, por motivos de alienação, descarte e até mesmo furto;

3) falta de controle dos itens patrimoniais recebidos em doação;

4) transferências internas de bens sem devida comunicação;

5) desconhecimento por completo da forma de como proceder, o devido controle do ativo imobilizado.

As discussões, mediadas pelo autor com o GE, deliberaram então que o problema apresentado era o de falta de controle interno, e, portanto um problema relacionado com a área administrativa, porém de competência da área contábil.

Em conclusão a esta primeira fase foi acordado junto aos chefes dos setores, que estes apresentariam num prazo estipulado, um relatório conforme planilha modelo sugerida pelo GE no Quadro 1. 
E.E. - ENTIDADE EM ESTUDO - RELAÇÃO DE BENS PATRIMÔNIAIS em MARÇO DE 2006.

\begin{tabular}{|c|c|c|c|c|c|c|c|c|c|}
\hline \multicolumn{2}{|c|}{ LOCALIZAÇÃO } & \multirow[b]{2}{*}{ QTDE } & \multirow[b]{2}{*}{ Descrição } & \multirow{2}{*}{$\begin{array}{l}\text { Categoria } \\
\text { do Bem }\end{array}$} & \multirow{2}{*}{$\begin{array}{l}\text { Número das } \\
\text { Plaquetas }\end{array}$} & \multicolumn{4}{|c|}{ OUTROS DADOS } \\
\hline Piso & $\begin{array}{c}\text { Complemento } \\
\text { / Setor }\end{array}$ & & & & & Marca & Modelo & Cor & $\begin{array}{l}\text { Estado } \\
\text { de Uso }\end{array}$ \\
\hline & & & & & & & & & \\
\hline & & & & & & & & & \\
\hline
\end{tabular}

Quadro 1 - Levantamento inicial de bens patrimoniais.

FONTE: Dados da pesquisa.

O setor de Contabilidade, também em data previamente estipulada, entregaria relatórios com os itens patrimoniais constantes dos registros contábeis.

O Grupo de Estudos (GE) ficou responsável por recrutar, selecionar e treinar número suficiente de voluntários (alunos) de um curso de Ciências Contábeis da cidade para participarem das etapas seguintes da Pesquisa-Ação.

\subsection{FASE PESQUISA APROFUNDADA}

Novamente em data previamente agendada, meados de 2006, o GE apresentou a equipe de voluntários que daria continuidade aos estudos.

Esta equipe de voluntários (EV) foi composta de 3 grupos com 3 voluntários e 1 coordenador cada, sendo que a EE disponibilizou local e um responsável para acompanhamento, totalizando assim 13 colaboradores para o estudo nesta fase.

De posse dos relatórios conforme modelo sugerido (Quadro 1), as equipes devidamente orientadas e de posse de material necessário (placas de identificação) iniciaram o trabalho de identificação dos bens patrimoniais, relacionando tais bens com o novo número de controle no novo modelo de planilha (Quadro 2).

\begin{tabular}{|c|c|c|c|c|c|c|c|c|c|c|}
\hline \multicolumn{2}{|c|}{ E.E. - ENTIDADE EM ESTUDO - RELAÇÃO DE BENS PATRIMÔNIAIS em MARÇO DE 2006.} \\
\hline \multicolumn{2}{|c|}{ LOCALIZAÇÃO } & \multirow{2}{*}{$\begin{array}{c}\text { Piso } \\
\text { Piso }\end{array}$} & $\begin{array}{c}\text { Complemento } \\
\text { / Setor }\end{array}$ & QTDE & Descrição & $\begin{array}{c}\text { Categoria } \\
\text { do Bem }\end{array}$ & $\begin{array}{c}\text { Número das } \\
\text { Plaquetas }\end{array}$ & & & \multicolumn{3}{|c|}{ OUTROS DADOS } & Plaquetas \\
\hline & & & & & & & & & \\
\hline & & & & & & & & & & \\
\hline
\end{tabular}

Quadro 2: Conferência do levantamento inicial de bens patrimoniais e emplaquetamento.

FONTE: Dados da pesquisa.

Embora semelhante à planilha inicial (Quadro 1), há que se destacar a inclusão da última coluna, "Plaquetas Anteriores", coluna esta que serviria de acompanhamento para efeito dos registros contábeis, e a coluna "Números das Plaquetas" seria utilizada para a nova numeração de controle do imobilizado para efeito de implantação do controle patrimonial.

Para se ter uma noção do estudo desenvolvido, este foi realizado durante um mês no período da tarde, em que foram vistoriados os seis pisos, mais o térreo da $E E$, além de três outras unidades externas.

As planilhas foram devidamente conferidas e em seguida digitadas, sendo utilizadas 1.745 plaquetas de identificação, 5 inutilizadas, remanescendo para uso posterior 1.250. Após essa etapa, com base nos registros contábeis fornecidos, foram identificados: os bens contabilizados, os considerados descartados (sem utilidade e/ou furtados), alienados e bens não constantes dos registros contábeis. 
Na conclusão desta segunda fase, denominada de pesquisa aprofundada, por meio do GE, o autor (responsável pelo GE) e a equipe de voluntários (EV - alunos) foi possível um aprofundamento no controle patrimonial, do qual foram tomadas decisões que direcionaram a terceira etapa de ação conforme descrita no tópico seguinte.

\subsection{FASE DA AÇÃO}

Já no final do ano de 2006, foram apresentados os relatórios do GE à diretoria Administrativa da EE, apontando os resultados que levariam as seguintes ações a serem tomadas:

1. Criação de um setor de controle dos bens patrimoniais;

2. Treinamento e conscientização da guarda e responsabilidade pelos bens patrimoniais;

3. Implantação de um sistema informatizado para controle dos bens patrimoniais;

4. Alterações dos registros contábeis quanto aos bens patrimoniais existentes(baixas inclusões e reavaliação).

Novo relatório foi sugerido quanto à avaliação dos bens para efeito de registro contábil, conforme modelo do Quadro 3.

\begin{tabular}{|c|c|c|c|c|c|}
\hline \multicolumn{5}{|c|}{ E.E. - ENTIDADE EM ESTUDO - CADASTRO DE BENS PATRIMONIAIS } \\
\hline Número das & Descrição & Datas de & No. das & Valor & Dados dos \\
\hline Plaquetas & dos Bens & Aquisição & N. Fs. & dos Bens & Fornecedores \\
\hline & & & & & \\
\hline & & & & & \\
\hline
\end{tabular}

Quadro 3 - Planilha para efeito de controle de registro contábil de bens patrimoniais.

FONTE: Dados da pesquisa.

Esta planilha do quadro 3 sugerida para efeito de avaliação dos bens, serviu como suporte para efeito de registro contábil dos itens dos bens imobilizados da entidade em estudo, o que demonstrou a eficiência desta terceira fase com relação à implantação da ação modificadora, a qual gerou conhecimentos contábeis aplicados à resolução do problema detectado na primeira fase exploratória e posteriormente confirmada na segunda fase de aprofundamento. Assim restou a quarta fase de avaliação, a qual foi realizada coforme se descreve a seguir.

\subsection{FASE DA AVALIAÇÃO}

No início do ano de 2007, novas reuniões foram realizadas com a EE e o GE, ocasionando a continuidade dos estudos com nova realização das três fases anteriores, com a finalidade de avaliação das mudanças ocorridas em relação a todo estudo até então realizado.

Constatou-se e considerou-se satisfatória as seguintes mudanças e implementações:

1) Criação do setor de controle dos bens patrimoniais;

2) Conscientização da guarda e responsabilidade pelos bens patrimoniais. 
Outras mudanças ainda continuavam pendentes de conclusão, porém já em fase de implementação: 2a) Implantação de um sistema informatizado para controle dos bens patrimoniais; e 2b) Alterações dos registros contábeis quanto aos bens patrimoniais existentes (baixas, inclusões e reavaliação).

Já no ano de 2008, os estudos continuaram com maior ênfase nas conclusões quanto à implantação do sistema de controle informatizado e registros contábeis.

Como conclusão desta quarta fase, tanto o responsável pelo GE quanto o GE e a EE consideraram os resultados satisfatórios quanto aos objetivos alcançados. Entenderam ainda como sendo necessário o prosseguimento da pesquisa-ação, com a finalidade de proporcionar novos levantamentos de problemas existentes, para que a utilização de tal metodologia permita a implantação de ações inovadoras gerando assim novos conhecimentos para a organização como um todo.

\section{CONSIDERAÇÕES FINAIS}

O presente artigo teve como objetivo demonstrar a eficiência da Pesquisa-Ação na contabilidade, como metodologia formadora de soluções para os ambientes organizacionais. Assim a Pesquisa-Ação foi aplicada a um caso em uma Entidade Estudada (EE), detalhando-se cada uma das quatro fases: Exploratória, Aprofundada, Ação e Avaliação.

$\mathrm{Na}$ fase exploratória detectou-se na EE, que não havia nenhum controle dos itens patrimoniais, o que ocasionavam as seguintes situações: valores e itens contabilizados diferente dos bens patrimoniais realmente existentes, com incorreções nas demonstrações contábeis da entidade; itens patrimoniais não localizados, por motivos de alienação, descarte e até mesmo furto; falta de controle dos itens patrimoniais recebidos em doação; transferências internas de bens sem devida comunicação; desconhecimento por completo da forma de como proceder, o devido controle do ativo imobilizado.

$\mathrm{Na}$ fase da pesquisa aprofundada as planilhas foram devidamente conferidas e em seguida digitadas, sendo utilizadas 1.745 plaquetas de identificação, 5 inutilizadas, remanescendo para uso posterior 1.250. Após, com base nos registros contábeis fornecidos, foram identificados: os bens contabilizados, os considerados descartados (sem utilidade e/ ou furtados), alienados e bens não constantes dos registros contábeis.

$\mathrm{Na}$ fase da Ação foram apresentados os relatórios do Grupo de Estudos à diretoria Administrativa da Entidade em Estudo, apontando os resultados que levariam asseguintes ações a serem tomadas: 1) Criação de um setor de controle dos bens patrimoniais; 2) Treinamento e conscientização da guarda e responsabilidade pelos bens patrimoniais; 3) Implantação de um sistema informatizado para controle dos bens patrimoniais; 4) Alterações dos registros contábeis quanto aos bens patrimoniais existentes (baixas inclusões e reavaliação).

$\mathrm{Na}$ fase da avaliação constatou-se e considerou-se satisfatória as seguintes mudanças e implementações: 1) Criação do setor de controle dos bens patrimoniais; e 2) Conscientização da guarda e responsabilidade pelos bens patrimoniais. Outras mudanças ainda continuavam pendentes de conclusão, porém já em fase de implementação: 1) Implantação de um sistema informatizado para controle dos bens patrimoniais; e 2) Alterações dos registros contábeis quanto aos bens patrimoniais existentes (baixas, inclusões e reavaliação).

Percebeu-se a importância da pesquisa-ação, tendo em vista que além de solucionar - problema detectado, ainda sugeriu algumas mudanças que são importantes para a administração da entidade, além de provê-los com informações úteis e fundamentais para o sucesso daquela instituição no controle do seu patrimônio. Por outro lado, este trabalho 
demonstrou a viabilidade da Pesquisa-Ação na contabilidade, enquanto técnica de pesquisa, cuja capacidade de superar impasses entre a teoria e a prática, por meio da interação e exploração de ambas é capaz de formar soluções para os ambientes organizacionais.

\section{REFERÊNCIAS}

ARGYRIS, C. Enfrentando Defesas Empresariais. Rio de J aneiro: Campus, 1992.

BASKERVILLE, R. L. WOOD-HARPER, A. T. A critical perspective on action research as a method for information systems research. Journal of Information Technology, v. 11, $\mathrm{n}$. 3, p. 235-246, set. 1996.

BRASIL. Lei Ordinária n. 9.790 de 23 de março de 1999. Brasília, DF: Senado, 1999.

BRUYNE, Paul de, et al. Dinâmica da pesquisa em ciências sociais: os pólos da prática metodológica. 5.ed. Rio de J aneiro: Francisco Alves, 1991.

BUNGE, Mario. Teoria e realidade. São Paulo: Perspectiva, 1974.

CONSELHO REGIONAL DE CONTABILIDADE DO ESTADO DE SÃO PAULO. Curso Básico de Auditoria. São Paulo: Atlas, 1988.

COLAUTO, Romualdo Douglas; BEUREN, Ilse Maria. Proposta para Avaliação da Gestão do Conhecimento em Entidade Filantrópica: o Caso de uma Organização Hospitalar. RAC, v. 7, n. 4, Out./ Dez. 2003.

ELDEN, M. \& CHISHOLM, R. Emerging Varieties of Action Research: Introduction to the Special Issue. Human Relations 1993, 46, 2, p. 121-41.

GAJ ARDO, Marcela. Pesquisa participante na América Latina. São Paulo: Brasiliense, 1986.

GAMBOA, Silvio Ancizar Sanches. Epistemologia da pesquisa em educação. Campinas, 1987. 229f. Tese (Doutorado em XXXX) - Faculdade de Educação da Universidade de Campinas, Campinas, 1987.

GOPAL, Abhij it. PRASAD, Pushkala. Understanding GDSS in symbolic context: shifting the focus from technology to interaction. MIS Quarterly, v. 24, n. 3, p. 509-546, set. 2000.

HATTEN, R.; KNAPP, D.; SALONGA, R. Action Research: Comparison with the Concepts of "The Reflective Practitioner" an "Quality assurance". Action Research Electronic Reader. Disponível em বhttp:// www. scu.edu.au/schools/gcm/ar/arr/ arow/rdr.html>. Acesso em: 31 out. 2008.

KIDDER, Louise H. (Org.). Métodos de pesquisa nas relações sociais. 2.ed. São Paulo: Brasiliense, 1987.

LAU, Francis. Toward a framework for action research in information systems studies. Information Technology \& People, v. 12, n. 2, p. 148-175, 1999.

LINDA, Dickens \& KAREN, Watkins. Action research: Rethinking Lewin Management Learning. Thousand Oaks; Jun 1999; Geographic Names - US.

LINDGREN, Rikard. HENFRIDSSON, Ola. SCHULTZE, Ulrike. Design principles for competence management systems: a synthesis of an action research study. MIS Quarterly, Minnesota, V. 28, n.3, p. 435-472, set. 2004.

LOPES, Jorge Expedito de Gusmão; RIBEIRO FILHO, Jose Francisco; PEDERNEIRAS, Marcleide Maria Macêdo ; RIBEIRO, Izabel de Barros . Pesquisa-Ação: Uma Abordagem para a Produção 
do Conhecimento Científico em Ciências Contábeis. Academia Revista de Divulgação Em Ciências Jurídicas e Contábeis, v. 1, 1, p. 115-124, 2006.

MARTINS, Gilberto de Andrade. Manual para elaboração de monografias e dissertações. São Paulo: Atlas, 2000.

MARTINS, Gilberto de Andrade; THEÓPHILO, Carlos Renato. Metodologia da investigação científica para ciências sociais aplicadas. São Paulo: Atlas, 2007.

MARTENSSON, Pär. LEE, Allen S. Dialogical action research at omega corporation. MIS Quarterly, v. 28, n. 3, p. 507-536, set. 2004

PEREIRA, E. M. A. Professor como pesquisador: o enfoque da pesquisa-ação na prática docente. In: GERALDI, C. M. G.; FIORENTINI, D.; PEREIRA, E. M. A. (Orgs.) Cartografias do trabalho docente - professor (a) - pesquisador (a), 2.ed., Coleção Leituras no Brasil, Ed. Mercado das Letras: Associação de Leitura do Brasil AB, Campinas, SP, 153 - 181, 2001.

PEREIRA, José Santos. Sistemas empresariais integrados - Erp na empresa contábil: um estudo de caso de mudança organizacional com o uso da pesquisa-ação. São Paulo, 2003. 293 f. Dissertação (Mestrado em Controladoria). Faculdade de Economia, Administração e Contabilidade da Universidade de São Paulo, São Paulo, 2003.

SCOTT, J. L. Stimulating awareness of actual learning processes. The Journal of the Operational Research Society, v. 53, n. 1, p. 2-10, jan. 2002.

SUSMAN, Gerald I. EVERED, Roger D. An assessment of the scientific merits of action research. Administrative Science Quarterly, v. 23, n. 4, p. 582-603, dez. 1978.

THEÓPHILO, Carlos Renato. Pesquisa Científica em Contabilidade: Desenvolvimento de uma Estrutura para Subsidiar Análises Crítico-Epistemológicas. In: $7^{\circ}$ Congresso USP de Controladoria e Contabilidade e do $4^{\circ}$ Congresso Usp de Iniciação Científica em Contabilidade, 2007, São Paulo. $1^{\circ}$ Congresso da ANPCONT - Associação Nacional dos Cursos de Pós-Graduação em Ciências Contábeis, 2007. Anais..., São Paulo, 2007.

THIOLLENT, Michael. Metodologia da pesquisa-ação. 11.ed. São Paulo: Cortez. 2002.

THIOLLENT, Michel. Pesquisa-ação nas organizações. São Paulo: Atlas São Paulo: Atlas, 1997. 


\section{ENDEREÇO DOS AUTORES:}

Câmara Municipal de Vereadores de Gaspar -SC

Avenidade das Comunidades, 133 - Centro

89110-000 - Gaspar, SC - Brasil - Caixa-Postal: 29

Universidade Estadual de Londrina, Centro de Estudos Sociais Aplicados.

Rod. Celso Garcia Cid (PR-445), KM 380

Campus Universitário

86051-990 - Londrina, PR - Brasil - Caixa-Postal: 6001

Exército Brasileiro, $23^{\circ}$ Batalhão de Infantaria.

Rua Amazonas s/ $\mathrm{n}$ - Garcia

89022-000 - Blumenau, SC - Brasil

Fundação Universidade Regional de Blumenau.

Rua Antonio da Veiga, 140

Victor Konder

89012-900 - Florianopolis, SC - Brasil 